\title{
INFLUENCE OF PRODUCTION PROCESES ON METALLURGICAL AND MECHANICAL PROPERTIES OF MILD STEEL
}

\author{
1, "DUROJAYE R.O., ${ }^{2}$ ADEFUYE O.A., ${ }^{2}$ RAJI N.A., ${ }^{2}$ OYETUNJI E.O. \\ ${ }^{1}$ Department of Structures and Aerodynamics, National Space Research and Development \\ Agency, Lagos, Nigeria \\ ${ }^{2}$ Department of Mechanical Engineering, Lagos State University, Ojo, Nigeria \\ *e-mail: lekandurojaye@gmail.com
}

Received:13 ${ }^{\text {th }}$ October 2020

Accepted: $26^{\text {th }}$ January 2021

Published: $24^{\text {th }}$ March 2021

https://doi.org/10.47545/etri.2021.6.1.069

\begin{abstract}
It is highly sacrosanct to have a thorough understanding of the effects of high temperature on some of the properties of mild steel materials. Most designers make use of raw data obtained from design manual at room temperature while carrying out engineering design analysis. Moreover, at high temperature, some of these properties do not fall within the range as expected at room temperature; therefore, any design analysis carried out based on such data will definitely have some error margin. It is therefore very important for designers of engineering components or equipment to put these considerations in their designs in order to avoid component or equipment premature or untimely failure. In order to achieve this goal, samples of mild steel material originally purchased for the construction of equipment were subjected to various metallurgical and mechanical tests. Samples from the fabricated equipment were equally subjected to similar tests using standard test facilities and equipment. Results obtained were compared so as to ascertain the effects of production processes such as machining, flame cutting, welding etc on the original mild steel material. Results obtained from these tests show that the carbon content ofthe fabricated equipment has slightly increased and as a result, an increase in hardness value was also discovered. The wear rate of the fabricated material also increased when compared to that of the original mild steel material. The ultimate tensile strength of the material dropped significantly due to production processes undergone by the material. Results from scanning electron microscopy also revealed changes in micro structure of the material. The study demonstrated the need to make use of appropriate data in engineering analysis for the design of engineering components and equipment.
\end{abstract}

Keywords: Scanning Electron Microscopy, Ultimate tensile strength, wear, hardness, Metallurgical.

\section{INRODUCTION}

Designers and fabricators of engineering products should be very conversant with the various changes' materials undergo during production and fabrication processes. The effects of these changes have a major role to play in the failure modes of the end product which eventually will determine the life span of the product [1]. Metallurgical factors are the condition of the metal, such as inclusions, chemical segregations, cold work and others, which have an impact upon the rate of electrochemical corrosion rates. These factors greatly influence the physical and mechanical properties of metals that are considered in their selection for design purposes $[2,9,10]$.

One of the common considerations in selecting materials is determining the desired mechanical properties. For instance, having a fracture-tolerant component is often an objective that can be achieved by selecting a material that is ductile and flaw tolerant, reducing the likelihood of brittle fracture $[3,11]$. The trade-off is that ductility is often achieved by sacrificing overall strength, wear resistance, and resistance to deformation. In order to achieve ductility and maintain wear resistance, one may select a surface treating process such as a case-hardening process $[4,6] . I n$ metals, some of the properties that must be considered to both ensure the desired function and reduce the likelihood of failures include: Tensile strength, yield strength, modulus of elasticity, ductility (percent elongation) , fatigue strength, fracture toughness, hardness, shear strength, machinability, coefficient of friction, impact strength , corrosivity, density, coefficient of thermal expansion, thermal conductivity, electrical resistivity, and other physical properties $[1,3,4,5]$.

The electrical, magnetic and structural properties of metals can be changed through heating, and as the applications of metal are diverse, different environments select different qualities [5]. For example, in engineering applications, 
toughness is preferred; in electrical applications, low electrical resistivity is significant. There are a number of ways of heating metal which are usually used to convert these properties. The temperature to which the metal is heated and the rates of cooling are cautiously controlled to accomplish the anticipated outcome [6]. Metal always expands when heated to certain temperature. Length, surface area and volume will rise with increased temperature. The scientific word for this is thermal expansion. The degree of thermal expansion differs with different types of metal. Thermal expansion takes place because heat raises the vibrations of the atoms in the metal as they are rapidly colliding with one another. Accounting for thermal expansion is vital when designing metallic members and structures. An everyday example is the design of household pipes, which must accommodate expansion and contraction as the times changes [5,7,12].Metals are comprised of a regular structure of atoms known as an allotrope. Heating the metal will relocate atoms from their position and the displaced atoms form a fresh structure which is known as allotropic phase transformation. Allotropic phase transformation changes properties of metals such as stiffness, strength and ductility. The most important allotropic phase transformation is experienced by iron. When iron is heated beyond 1,675 degrees Fahrenheit it is capable of engaging more carbon, which is an ingredient that will raise the hardness of any steel product. This anticipated effect is used in numerous types of High Carbon (above 0.50 carbon) steel $[7,8,13]$.

In order to ascertain the various changes that metals undergo as a result of increase in temperature due to different fabrication processes, they are subjected to during production; several tests were carried out using standard test facilities and equipment. For the ease of identification, the test materials were categorized as sample A and sample B. Sample A are samples of material taken from the original mild steel material used for the production of the component or equipment while sample B are samples of materials taken from the fabricated or finished equipment.

\section{EXPERIMENTAL PROCEDURES}

\subsection{Material}

Specimen: The specimens used for chemical analysis, hardness and wear test were cut into $5 \mathrm{~mm} \times 5 \mathrm{~mm}$ and $3 \mathrm{~mm}$ in thickness polished with a rotary grinder. The specimen used for optical microscopy and scanning electron microscopy was $5 \mathrm{~cm} \times 6 \mathrm{~cm} \times 3 \mathrm{~mm}$ in thickness for both samples. For tensile test, the sample was cut to; Length $55 \mathrm{~mm}$, thickness $3 \mathrm{~mm}$ and width $5 \mathrm{~mm}$.

Equipment: The following equipment were used for the study.

Optical microscope for visualization at low magnification, scanning electron microscope for visualization at high magnification, Argon analyzer for chemical analysis, Vickers hardness testing machine for harness test, an Instron $3369^{R}$ testing machine equipped with an electromechanical sensor for control of tensile strain in the active zone of samples in the load range up to $10 \mathrm{kN}$ was used. Wear testing machine was also used to carry out test on samples.

\subsection{Method}

Optical microscopy: Optical Microscopy was carried out on both samples at a very low magnification (600x), this was to examine the micro structure of both material for comparison. Optical Microscopy is a very important test that can help to determine some material characteristics such Morphology (shape and size), phase distribution (amorphous or crystalline), transparency or opacity.

Sample A and B were prepared for metallography work using emery papers of 240, 320, 400 and 600 grit papers and then polished with emery cloth using silicon carbide solution of 1 and 0.5 micron. They were then etched with $2 \%$ NITAL and viewed with metallurgical microscope.

Scanning Electron Microscopy: Scanning electron microscopy was carried out on both materials at very high magnification ranging from $7000 x$ to $9000 x$. This was to examine the micro structure of the material at very high magnification and to see the effects of production process on the finished product. The scanning electron microscope (SEM) is one of the most versatile instruments available for the examination and analysis of the microstructure morphology and chemical composition characterizations of materials. Samples of materials were prepared to the required specifications, and were scanned on the SEM machine.

Chemical Analysis: Chemical Analysis test was carried out using argon analyzer. The purpose of this test was to examine the chemical composition of materials from the parent mild steel samples and materials from the finished product. Comparison was then made with standard chemical composition of mild steel material in order see the possible effects of the production processes on the combustion chamber as compared with the parent material used for the construction. 
Hardness Test: Vickers hardness test was conducted on both samples in order to see the effects on the hardness levels of the materials as a result of the heat treatment process undergone by the material during production processes. The samples were cut to size and polished on a rotary grinder before they were mounted on the test machine.

Tensile Test: Tensile test was carried out using Instron $^{\mathrm{R}} 3369$ testing equipment on both samples with the following specifications; Length $55 \mathrm{~mm}$, thickness $3 \mathrm{~mm}$ and width $5 \mathrm{~mm}$. The purpose was to examine the changes in the tensile strength of the materials due to heat treatment processes undergone during production processes. Samples of the parent mild steel material and samples of the finished product were subjected to tensile test using Instron $^{\mathrm{R}} 3369$ testing machine equipped with an electro-mechanical sensor for control of tensile strain in the active zone of samples in the load range of up to $10 \mathrm{kN}$.

Wear Test: Wear is the process of gradual removal of material from the surfaces of the specimen. The detached material becomes loose wear debris. Five specimens were extracted from the material used to construct the equipment and were labeled A1, A2, A3, A4 and A5. The specimen was mounted on the wear testing machine one at a time with a load of $10 \mathrm{~N}$ through a sliding distance of $3 \mathrm{~mm}$. Results obtained were used to calculate the specific wear rate of all the specimens and the average specific wear rate was also determined. Similarly, five specimens were also extracted from the finished product and labeled B1, B2, B3, B4 and B5. They were also tested on the wear testing machine and results generated were used to calculate the specific wear rate for the entire specimen and an average specific wear rate was calculated.

\section{RESULTS AND DISCUSSIONS}

The influence of production processes on the microstructure of the mild steel material was explored in the optical micrograph and the scanning electron microscopy images.

\subsection{Optical Microscopy}

The optical micrographs for the material used before processing and after processing are as shown in Figures 1 and Figure 2.

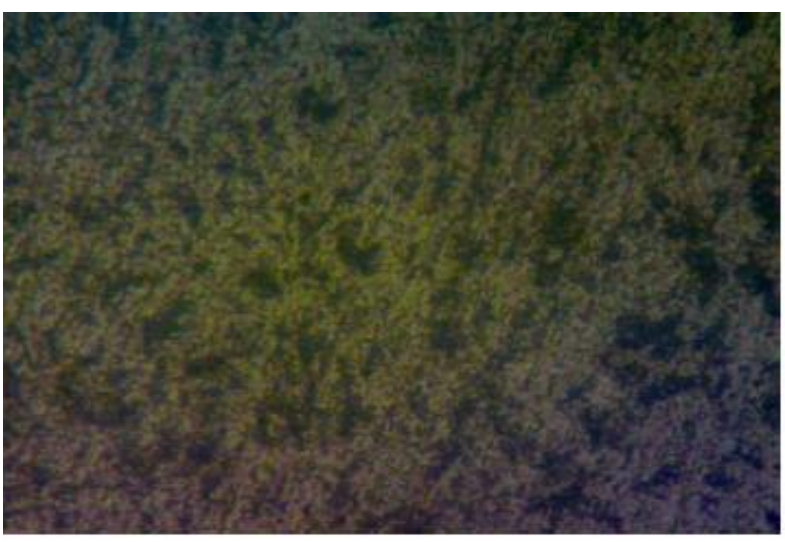

Figure 1. Optical Microscopy Image of Sample A

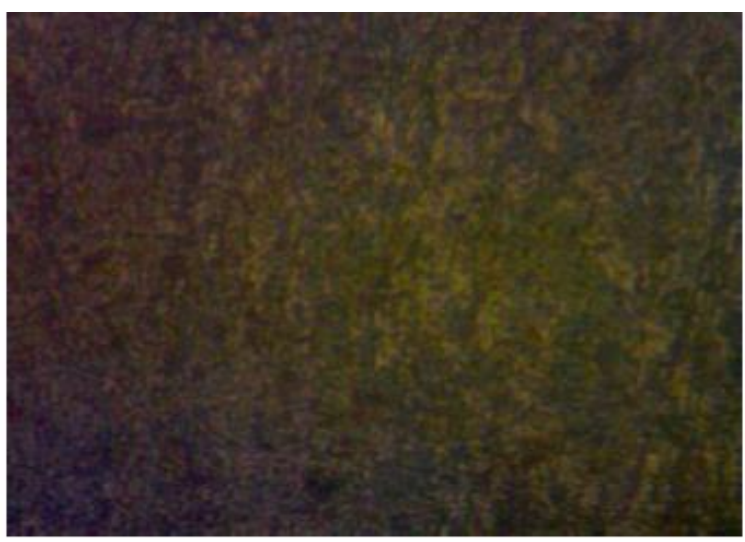

Figure 2. Optical Microscopy Image of Sample B

The sample A has microstructure that has coarse ferrite and pearlite which is acicular in nature. The pearlite is scattered in the ferrite region. The ferrite phase is more dominant in the microstructure and is more in number compared with the pearlite phase and the implication is that the material is more ductile. Sample B has undergone some forms of heat treatment changes due to production processes which have affected its microstructure. The microstructures contain ferrite, martensite and linked creep cavities with distinct grain boundaries. The magnification for both samples was 600x.

The image of the SEM at a magnification of 9000x for sample A is as shown in Figure 3 and the SEM imageat a magnification of 9000x for sample B is shown in Figure 4. 


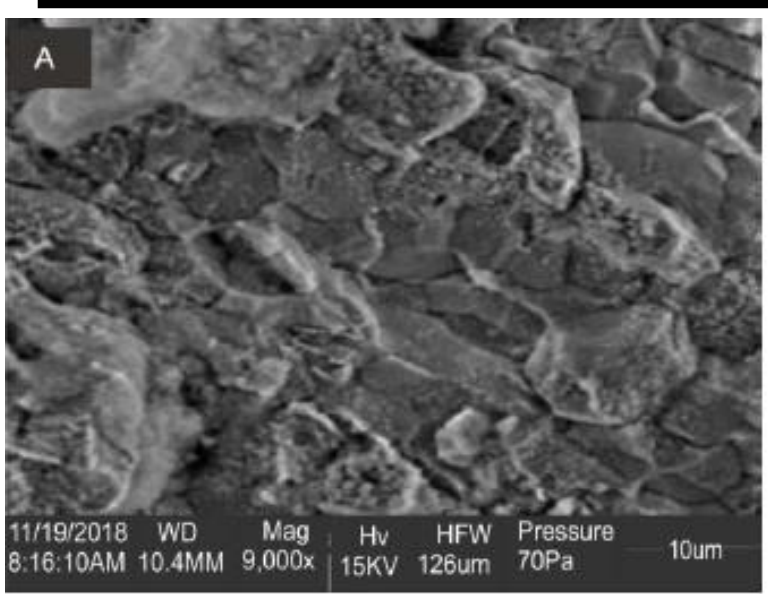

Figure 3. SEM Image from Sample A

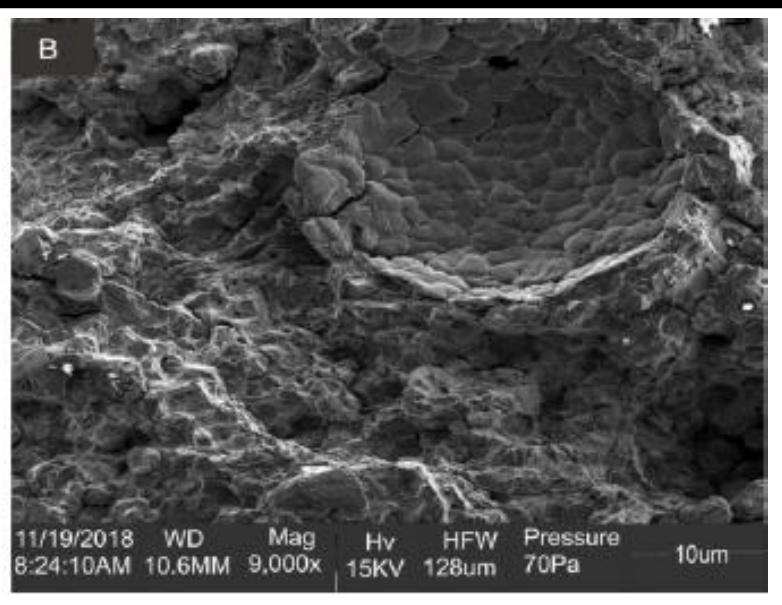

Figure 4. SEM Image from Sample B

The SEM results of sample B as shown in Figure 4 shows that finer grains are formed due to heat treatment during production.

\subsection{Chemical Analysis}

From the chemical analysis results obtained, the grade of mild steel that was used for the construction of the equipment was revealed as "1020" as shown in Figure 1 and Figure 2. This class of mild steel was not initially known before the construction as material was picked from the open market. Critical examination of this results shows that there were slight changes in the chemical composition of sample A which was the parent material that was used for the construction of the equipment. The carbon content in increased from $0.0185 \%$ to $0.0294 \%$ and the manganese content also increased from $0.2372 \%$ to $0.3227 \%$, while a slight decrease in silicon and aluminum content were noticed. These changes were as a result of the production processes undergone by sample B material which were material from the finished product.

Table 1. Chemical composition of Sample A

\begin{tabular}{|c|c|c|c|c|c|c|c|c|}
\hline & $\mathbf{F e}$ & C & $\mathbf{S i}$ & Mn & $\mathbf{P}$ & $\mathbf{S}$ & $\mathrm{Cr}$ & $\mathbf{N i}$ \\
\hline & 99.54 & 0.0185 & 0.0106 & 0.2372 & $<0.000$ & $<0.000$ & $<0.007$ & $<0.005$ \\
\hline Avg & 99.52 & 0.0172 & 0.0151 & 0.2425 & $<0.000$ & $<0.000$ & 0.0098 & 0.007 \\
\hline \multirow[t]{3}{*}{ SD } & 0.0124 & 0.0023 & 0.0034 & 0.005 & 0 & 0 & 0.002 & 0.0027 \\
\hline & Mo & $\mathbf{C u}$ & Al & $\mathbf{T i}$ & $\mathbf{V}$ & Co & $\mathbf{N b}$ & $\mathbf{W}$ \\
\hline & $<0.000$ & 0.0165 & 0.0638 & $<0.000$ & $<0.000$ & $<0.000$ & $<0.000$ & $<0.000$ \\
\hline Avg & $<0.000$ & 0.0183 & 0.0653 & $<0.000$ & $<0.000$ & $<0.000$ & $<0.000$ & $<0.000$ \\
\hline \multirow[t]{3}{*}{ SD } & 0 & 0.0014 & 0.0027 & 0.0004 & 0 & 0 & 0 & 0 \\
\hline & Sn & C.E & & & & & & \\
\hline & $<0.003$ & 0.0628 & & & & & & \\
\hline Avg & $<0.002$ & 0.0638 & & & & & & \\
\hline SD & 0.0013 & 0.0026 & & & & & & \\
\hline
\end{tabular}


Table 2. Chemical composition of Sample B

\begin{tabular}{|c|c|c|c|c|c|c|c|c|}
\hline & $\mathrm{Fe}$ & C & $\mathbf{S i}$ & Mn & $\mathbf{P}$ & $\mathbf{S}$ & $\mathrm{Cr}$ & $\mathrm{Ni}$ \\
\hline & 99.47 & 0.0294 & $<0.000$ & 0.3227 & $<0.000$ & $<0.000$ & $<0.004$ & $<0.000$ \\
\hline Avg & 99.39 & 0.0584 & 0.0116 & 0.3322 & $<0.000$ & $<0.000$ & 0.0076 & $<0.000$ \\
\hline \multirow[t]{3}{*}{$\mathrm{SD}$} & 0.0177 & 0.0331 & 0.0021 & 0.0141 & 0 & 0 & 0.0048 & 0 \\
\hline & Mo & $\mathbf{C u}$ & Al & $\mathbf{T i}$ & $\mathbf{V}$ & Co & $\mathbf{N b}$ & $\mathbf{W}$ \\
\hline & $<0.000$ & 0.0141 & 0.0424 & $<0.000$ & $<0.001$ & $<0.000$ & $<0.000$ & $<0.016$ \\
\hline Avg & $<0.000$ & 0.0146 & 0.0468 & $<0.000$ & 0.0036 & $<0.000$ & $<0.000$ & $<0.030$ \\
\hline \multirow[t]{3}{*}{ SD } & 0 & 0.001 & 0.0048 & 0.0006 & 0.0027 & 0 & 0 & 0.0438 \\
\hline & Sn & C.E & & & & & & \\
\hline & $<0.000$ & 0.0853 & & & & & & \\
\hline Avg & $<0.001$ & 0.1189 & & & & & & \\
\hline SD & 0.0024 & 0.0366 & & & & & & \\
\hline
\end{tabular}

\subsection{Hardness Test}

Vickers Hardness test was carried out on samples of both materials, Sample A materials from the mild steel material used to produce the equipment and sample B materials from the finished equipment. Results obtained are seen in Table 3. From the Vickers hardness test results obtained, it was clearly seen that the hardness values of the finished has increased substantially from the parent material that was used to produce it. This can be attributed to the formation route undergone by the parent material during production processes. The repeated heating and force cooling of the material from elevated temperature must have been responsible for the increase in hardness values.

Table 3. Vickers Hardness Test Values of Sample A and B

\begin{tabular}{cc}
\hline Sample & Vickers Hardness \\
\hline A & 255.6 \\
B & 292.8 \\
\hline
\end{tabular}

\subsection{Tensile Test}

Mechanical properties of the finished product were evaluated in order to further ascertain the effects of production processes on the finished product material. From the results obtained it can be seen that the tensile strength of the mild material that was used to fabricate the equipment was far short of the standard value for the design analysis and sizing of the product. A further decline was noticed in the finished product material, an indication of the effects of heat treatment that was carried out on the material during formation process. Standard tensile strength used for design calculation was $400 \mathrm{MPa}$. The average tensile strength of five samples from the material used for fabrication from results obtained was $318.771508 \mathrm{MPa}$ and the average tensile strength of five samples from the finished product material was 232.121568 MPa. This can be seen in Figure 5 and Figure 6.

Figure 5 inferred that the strain values for sample A and sample B are quite different. Sample A which is the parent mild steel material has a longer strain value of $0,09 \mathrm{~mm}$ and sample B which is the failed combustion chamber material has a strain value of $0.047 \mathrm{~mm}$. When material hardens, they tend to lose their ductile nature and become brittle. The heat treatment processes undergone by the finished product material during fabrication process has increase the hardness of the mild steel material as seen from the hardness test results carried out at the University of Lagos. The loss of ductility made the material to be more brittle and as a result cannot undergo excessive strain before rupture. 


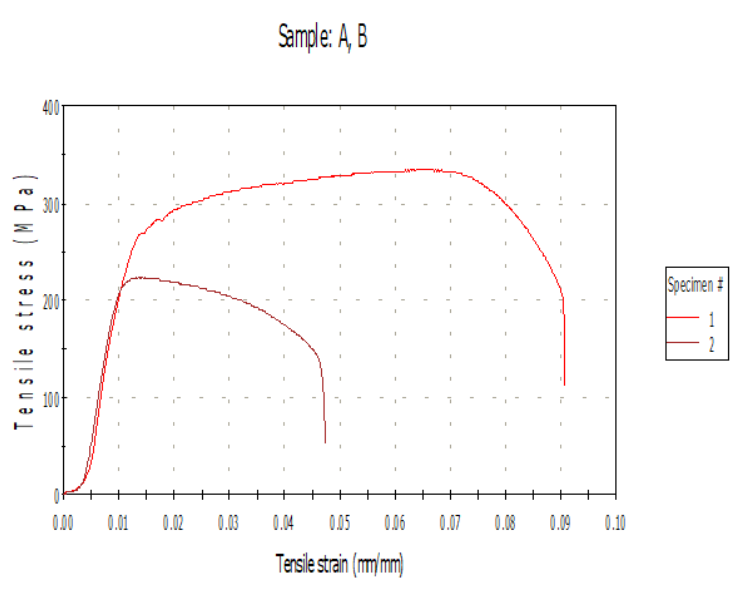

Figure 5. Ultimate Tensile Strength curve

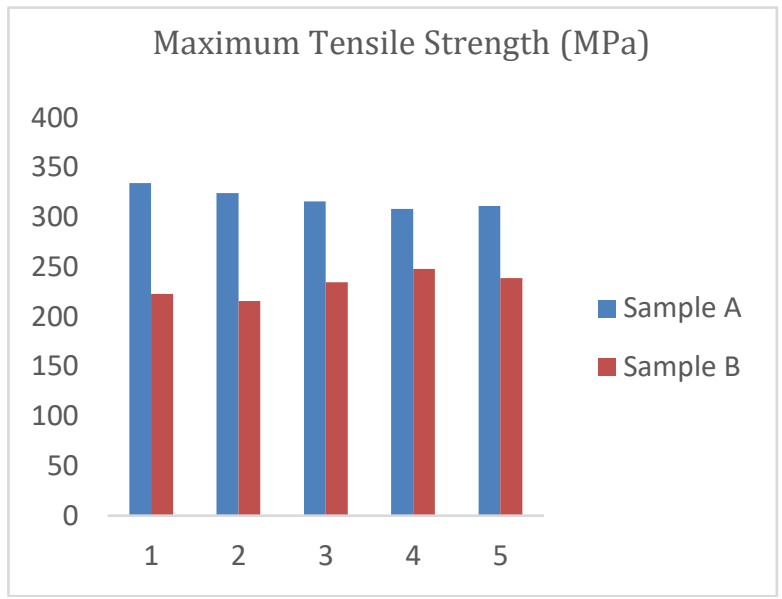

Figure 6. Graph of Ultimate Tensile Strength

\subsection{Wear Test}

Wear test of both materials was also conducted with a view to ascertaining the possible changes in the wear rate of the materials due to heat treatment that the material had undergone during production. Abrasive wear and fatigue wear results in significant reduction in the mechanical properties of the mild steel material. Abrasive wear results in loss of material by dynamic interaction of two surfaces with respect to one another. Material is removed from the surface resulting in loss of dimensions. From the results obtained as shown in the Table 4 and Figure 7.0 below, it can be seen that specific wear rate of all the samples used to construct the equipment was higher than the specific wear rate of samples from the finished product. The average specific wear rate of sample A that is material used for the construction of the equipment was $\mathbf{0 . 3 2}$ and the average specific wear rate of sample B that is the material from the finished was $\mathbf{0 . 1 1}$. This is a clear indication of the increase in the hardness value of the material from the finished product due to process undergone during fabrication. When material hardens, due to increase in carbon content, the rate of wear tends to decrease as seen from the results obtained from the wear test.

Table 4. Specific wear rate of Specimen

\begin{tabular}{|l|l|l|l|l|l|l|l|l|}
\hline Sample & $\begin{array}{l}\text { Initial } \\
\text { Weight } \\
\mathrm{a}\end{array}$ & $\begin{array}{l}\text { Final } \\
\text { Weight } \\
\mathrm{b}\end{array}$ & $\begin{array}{l}\text { Volu } \\
\mathrm{me}\end{array}$ & $\begin{array}{l}\text { Density } \\
\mathrm{d}\end{array}$ & $\begin{array}{l}\text { Weight } \\
\text { loss } \\
\mathrm{C}=\mathrm{a}-\mathrm{b}\end{array}$ & $\begin{array}{l}\text { Sliding } \\
\text { Distance } \\
(\mathrm{mm}) \\
\mathrm{S}\end{array}$ & $\begin{array}{l}\text { Vol loss } \\
\Delta \mathrm{V}=\mathrm{C} / \mathrm{d} \\
\mathrm{X} 1000\end{array}$ & $\begin{array}{l}\text { Specific } \\
\text { Rate } \\
\mathrm{W}_{\mathrm{S}}=\Delta \mathrm{V} / \mathrm{F} \times \mathrm{S}\end{array}$ \\
\hline A1 & 5.4092 & 5.3992 & 3.20 & 1.69 & 0.010 & 3.0 & 5.9 & 0.20 \\
\hline A2 & 5.4185 & 5.3965 & 3.21 & 1.68 & 0.022 & 3.0 & 13.09 & 0.40 \\
\hline A3 & 5.3826 & 5.3612 & 3.15 & 1.70 & 0.021 & 3.0 & 12.35 & 0.41 \\
\hline A4 & 5.3978 & 5.3855 & 3.22 & 1.67 & 0.012 & 3.0 & 7.18 & 0.24 \\
\hline A5 & 5.4215 & 5.4198 & 3.20 & 1.69 & 0.017 & 3.0 & 10.06 & 0.34 \\
\hline Average & & & & & & & & $\mathbf{0 . 3 2}$ \\
\hline B1 & 6.3561 & 6.3470 & 3.10 & 2.05 & 0.0091 & 2.3 & 4.4 & 0.19 \\
\hline B2 & 6.3475 & 6.3412 & 3.00 & 2.10 & 0.0063 & 2.3 & 3.0 & 0.13 \\
\hline B3 & 6.3326 & 6.3287 & 3.04 & 2.08 & 0.0039 & 2.3 & 1.8 & 0.078 \\
\hline B4 & 6.3517 & 6.3482 & 3.16 & 2.01 & 0.0035 & 2.3 & 1.7 & 0.075 \\
\hline B5 & 6.4128 & 6.4095 & 3.11 & 2.06 & 0.0033 & 2.3 & 1.6 & 0.069 \\
\hline Average & & & & & & & & $\mathbf{0 . 1 1}$ \\
\hline
\end{tabular}




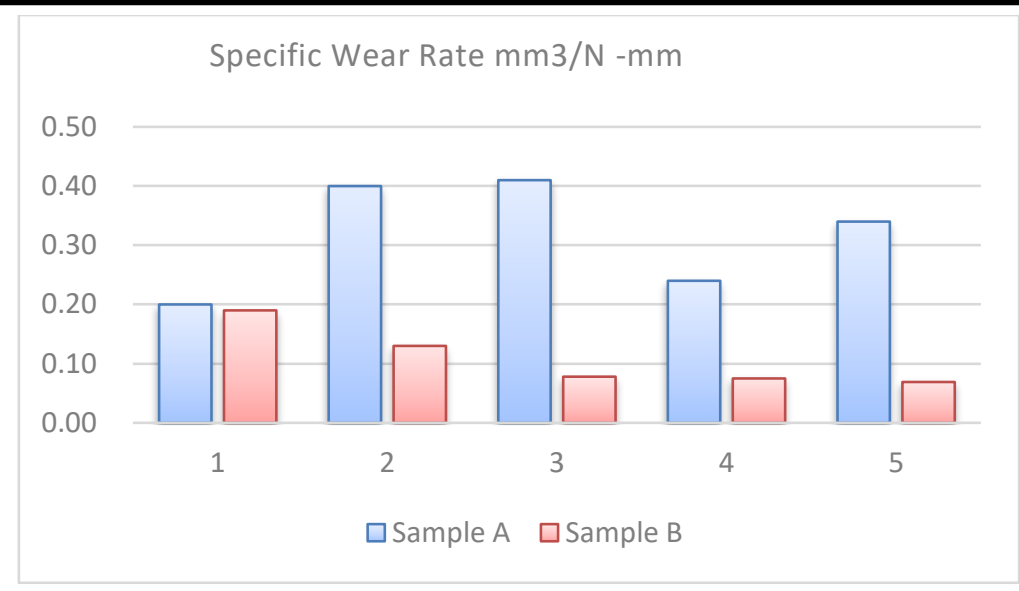

Figure 7. Specific wear rate of specimens A and B

\section{CONCLUSION}

The importance of carrying out a thorough research work into production and fabrication processes of engineering components and equipment cannot be over emphasized. The results obtained from the various test conducted on the material of the finished product show that engineering materials undergo changes during production or fabrication process. As a result, designers and fabricators of engineering products should be very conversant with the various changes materials undergo during production and fabrication processes. The effects of these changes have a major role to play in the failure modes of the end products which eventually will determine the efficiency and the life span of these products.

\section{REFERENCES}

[1] William D. Callister, Jr. (1994). Materials Science and Engineering: An Introduction, Third Edition (Toronto: John Wiley \& Sons, Inc.)

[2] Kathleen Mill ed. et al. (1993) Metallography and Microstructures, (Ohio:ASM Metals Handbook International)

[3] Giles F. Carter, Donald E. Paul, Totik, Y., Sadeler, R., Altun, H., Gavgali,M. (2003). The effects of induction hardening on wear properties of AISI 4140 steel in dry sliding conditions. Journal of Materials \& Design, 24(1): 25-30.

[5] Shigley, J. (1983). Mechanical Engineering Design.4th Edition, McGraw-Hill, New York, http://dx.doi.org/10.1115/1.3258702.

[6] Adefuye O.A., Raji N.A., Olaleye J.O., Kuku R.O. (2020). Influence of quenching and tempering heat treatment on tensile properties and toughness of cold-drawn $0.12 \mathrm{wt} \% \mathrm{c}$ steelEngineering \& Technology Research JournalVolume 5(2) pp. 17-24.

[7] ASM International 2006. Practical Heat Treating, Second Edition (\#05144G). Fundamental of the Heat Treating of Steel.

[8] Sahin, Y. (2006). Optimal testing parameters on the wear behavior of various steels Journal of Materials and design27(1):455-460.

[9] Waddell, J.N., Payne, A.G.T. and Kieser, J.A. (2010). Scanning Electron Microscopy Observations of Failures of Implant Over denture Bars: A Case Series Report. Clinical Implant Dentistry and Related Research, 12:26-38. 
[10] Giacomo, F., Giulio, R. (2014). Structural Aerospace Composite/Metallic Samples under Fatigue Loads: Experimental Activity on Three Case Studies, Journal of Mechanics Engineering and Automation4: 318-326.

[11] Lee, C.S., Lee, K.A., Li, D.M., Yoo ,S.J.,Nam, W.J. (1998). Microstructural influence on fatigue properties of a high-strength spring steel, material science and engineering241(1):30-37.

[12] Jaegu C., Chang-Sung S., Soo P., Gayeon K. (2019). Effect of high-temperature degradation on microstructure evolution and mechanical properties of austenitic heat-resistant steel. Journal of Materials research and Technology 8(2):2011-2020.

[13] Sanghoon N., Byoung-Kwon C., Chang-Hee H., Suk H.K., Jinsung J., Yong-hwang J., Tea k.k. (2013). Effects of Heat Treatments on Microstructures and Mechanical Properties of Dual phase ods Steels for High Temperature Strength. Nuclear Engineering and Technology 45(6):821-826. 